\title{
Quantification of Soil Organic Carbon - Comparison of Wet Oxidation and Dry Combustion Methods
}

\author{
V. Ramamoorthi and S. Meena*
}

Department of Soil Science and Agricultural Chemistry, Tamil Nadu Agricultural University, Coimbatore-641 003, Tamil Nadu, India

*Corresponding author

\section{A B S T R A C T}

\section{Keywords \\ Walkley and Black, Soil organic carbon, Heanes method, Dry combustion \\ Article Info \\ Accepted: \\ 04 September 2018 \\ Available Online: \\ 10 October 2018}

\begin{abstract}
Different methods of soil organic carbon (SOC) determination namely Walkley and Black (WB), Modified WB, Photometric, gravimetric and dry combustion methods were compared. Each method has its own advantages and limitations. Percentage of carbon recovered ranged from 51.03 to 110.13 and the calculated correction factor (CF) varied from 0.90 to 1.95 . Highly significant correlation (r) was obtained among all the SOC methods. The highest and lowest coefficient of determination $\left(\mathrm{R}^{2}\right)$ was found in Heanes photometric (0.91) and gravimetric methods (0.75), respectively. Therefore, Heanes photometric method can be a potential method to substitute the WB method, which is most widely used in Indian soil testing laboratories.
\end{abstract}

\section{Introduction}

Soil organic matter (SOM) improves the physical and chemical environment of the soil by holding moisture and thus supporting plant growth. It supplies plant nutrients, the release of which depends upon microbial activity. Carbon is the major constituent of organic matter; therefore SOC content is strongly related to the SOM levels. There are several methods to determine SOC (Chaterjee et al., 2009). Reason to choose certain technique depends on the reliability, reproducibility, time efficiency, cost of equipment (or) chemicals and the possible environmental risk associated with the method. The variable chemical composition of the soil organic matter further complicates its assessment (Hesse, 1971).

The methods of soil organic carbon quantification are generally classified into two types viz., wet digestion and dry combustion methods. In wet digestion method, $48-58 \%$ of carbon in the soil is oxidized by potassium dichromate by utilizing the heat of dilution of sulphuric acid (Walkley and Black, 1934) based on Schollenberger method (Schollenberger, 1927).

The WB method has been the most widely used and reported procedure in India (Bhattacharya et al., 2015) because of its relatively quick and simple protocol but the accuracy remains an issue (Gelman et al., 
2012). The major limitation of this method is that the recalcitrant fraction of the soil organic matter is not determined and the underestimation of SOC necessitates the use of a correction factor. Nelson and Sommers (1982) stated that WB procedure results in an approximate (or) semi-quantitative estimate of analyzed SOC because of the lack of correction factor (De Vos et al., 2007).

The WB method claims to estimate organic carbon to an extent of $77 \%$ and to make it $100 \%$, it is multiplied with the correction factor of 1.29, known as Walkley and Black Recovery Factor (WB-RF). However, this factor varies among soils, their management regimes and soil horizons (Tabatabai, 1970). Mikhailova et al., (2003) reported a wide variation in correction factor from 1.09 to 2.27 for Russian top soils.

Through the application of external heat in WB protocol (Modified WB method), more recovery has been reported due to complete oxidation of soil organic carbon (Meibus, 1960).

As a simple, quick and novel method for SOC determination, measurement of absorbance of green chromium (III) complex generated in potassium dichromate wet oxidation process using colorimetric principle was developed (Heanes, 1984; Walinga et al., 1992; Nelson and Sommers, 1996).

In dry combustion method, incinerating SOM and thermal decomposing carbonate minerals generate carbon dioxide $\left(\mathrm{CO}_{2}\right)$ that is measured by (1) dry combustion followed by measuring the changes or mass loss on ignition (LOI) and, (2) dry oxidation of SOC, and determining the evolved carbon with automated instruments (Chatterjee et al., 2009). Both methods involve oxidizing SOC at a high temperature. The LOI entails heating the sample in a muffle furnace between 200- $500^{\circ} \mathrm{C}$. In this method, overestimation of $\mathrm{OC}$ can occur because minerals in soil lose structural water at certain temperature. It has been concluded that LOI is a practical and reliable method for quantifying SOC (Kamara et al., 2007) and is a rapid, simple, low cost and environmentally friendly method (Wang et al., 2012).

Dry oxidation via automated analyzer is accomplished between $950-1150^{\circ} \mathrm{C}$. The automated analyzer allows for rapid and reliable determination method based on dry combustion principle and does not use ant toxic reagents and would be ideal in view of current environmental concerns (Chatterjee $e t$ al., 2009). This method is currently considered as the most reliable, with recoveries close to $100 \%$ (Lettens et al., 2007), and it is used as reference method.

Wider existence of soil carbon ranges necessitate the need for high volume, more accurate method that is capable to measure incremental changes in soil organic carbon (Wright et al., 2007). Aim of this work was to (i) Compare different methods of SOC estimation (ii) and to determine the recovery and correction factor that are appropriate for the soils under various agro-climatic conditions of Tamil Nadu.

\section{Materials and Methods}

\section{Soil sampling}

Fifty geo referenced soil samples were collected at $0-15 \mathrm{~cm}$ depth representing various agro climatic regions and soil types of Tamil Nadu. The latitude coordinates of sampled locations, range from $11.1271^{\circ} \mathrm{N}$ and $78.6569^{\circ}$ E. The collected soils were air dried and passed through a $2 \mathrm{~mm}$ sieve for routine chemical analysis and $0.5 \mathrm{~mm}$ sieve for organic carbon estimation. Each sample was analyzed for organic carbon following WB, 
modified WB, photometric, gravimetric and dry combustion methods.

\section{Walkley and Black method (Walkley and Black, 1934)}

Walkley and Black method relies on oxidation of organic matter by potassium dichromate $\left(\mathrm{K}_{2} \mathrm{Cr}_{2} \mathrm{O}_{7}\right)$ that is acid catalyzed. The heat of dilution by the acidified dichromate raises the temperature sufficiently to induce a substantial but not complete oxidation of soil $\mathrm{C}$ to $\mathrm{CO}_{2}$. Then the excess dichromate was quantified by back titrating against ferrous ammonium sulphate (FAS). The percentage WB carbon is given by the formula:

$W B(\%)=M \times \frac{\left(V_{1}-V_{2}\right)}{W} \times 0.30 \times C F$

Where, M is the molarity of the FAS solution (from blank titration), $\mathrm{V}_{1}$ is the volume of FAS required in blank titration, $V_{2}$ is the volume FAS required in actual titration, $\mathrm{W}$ is the weight $(\mathrm{g})$ of the oven-dried soil sample and $\mathrm{CF}$ is the correction factor. The $\mathrm{CF}$ is a compensation factor for the incomplete oxidation and is the inverse of the recovery percentage.

\section{Modified WB method - Meibus method (Meibus, 1960)}

The same procedure like WB was followed, but the digestion mixture of $\mathrm{K}_{2} \mathrm{Cr}_{2} \mathrm{O}_{7}$ with sulphuric acid $\left(\mathrm{H}_{2} \mathrm{SO}_{4}\right)$ was subjected to external heating on an electric plate at $100^{\circ} \mathrm{C}$ for 30 minutes under reflux. The excess dichromate was titrated with ferrous ammonium sulphate.

\section{Photometric method (Nelson and Sommers, 1996)}

One gram of soil was taken and placed in a $250 \mathrm{~mL}$ Erlenmeyer flask and $10 \mathrm{~mL}$ of $1 \mathrm{~N}$ potassium dichromate and $10 \mathrm{~mL}$ of $5 \mathrm{M}$
$\mathrm{H}_{2} \mathrm{SO}_{4}$ were added and the suspension was stirred in circular motion using a horizontal shaker for 10 minutes at $180 \mathrm{rpm}$. After shaking, the suspension was allowed to remain undisturbed for one hour and then $50 \mathrm{~mL}$ of distilled water was added.

The absorption of supernatant solution was measured in a spectrophotometer at $660 \mathrm{~nm}$. The calibration curve was prepared using different concentrations of sucrose solution $(0$, $0.05,0.15,0.30,0.50 \mathrm{ppm})$.

\section{Photometric method (Heanes, 1984)}

About 0.5 gram of soil was transferred to 100 $\mathrm{mL}$ digestion tube and $10 \mathrm{~mL}$ of $1 \mathrm{~N} \mathrm{~K}_{2} \mathrm{Cr}_{2} \mathrm{O}_{7}$ was added followed by $20 \mathrm{~mL}$ concentrated $\mathrm{H}_{2} \mathrm{SO}_{4}$ and the tubes were swirled gently to avoid localized boiling. The mixture was digested at $135^{\circ} \mathrm{C}$ for 30 minutes and the contents were allowed to cool. The tubes were stoppered and inverted several times and after a further period of cooling, the volume was made up to $100 \mathrm{~mL}$. An aliquot of $10 \mathrm{~mL}$ was taken and centrifuged and the absorption of the clear supernatant solution was measured at $660 \mathrm{~nm}$ using spectrophotometer with sucrose as standard solution.

\section{Gravimetric method - loss on ignition (LOI)}

Five grams of soil that passed through a sieve of $2 \mathrm{~mm}$ mesh was further dried at $105^{\circ} \mathrm{C}$ for 24 hours then the samples were subjected to calcinations for 5 hours at $400^{\circ} \mathrm{C}$ (Miyazawa et al., 2000). Subsequently, the samples were weighted and the difference between the initial and final mass corresponded to the organic matter of the soil. Organic carbon values were derived from the regression model.

$$
\begin{aligned}
& \mathrm{OM}(\%)=\frac{W_{105}-W_{400}}{W_{105}} \times 100 \\
& \mathrm{Y}_{\mathrm{CHNS} / \mathrm{O}}=2.5637+0.6306 \mathrm{C}_{\mathrm{OM}}
\end{aligned}
$$




\section{Dry combustion - Elemental analysis (CHNS/O)}

Thirty milligram $(30 \mathrm{mg})$ of soil ground up so as to pass through a $0.2 \mathrm{~mm}$ mesh sieve was placed in a tin capsule and combusted at $975^{\circ} \mathrm{C}$ based on the Pregl-Dumas method. An automatic analyzer model PE 2400 series II CHNS/O (Perkin Elmer, CT, USA) equipped with a thermo conductivity sensor detector (TCD) was used. All samples were pre-treated with $\mathrm{HCl}$ in order to remove inorganic $\mathrm{C}$.

\section{Recovery factor and correction factor}

The percentage recovery (RC) was computed by expressing the SOC obtained by a particular method as a percentage to the SOC value obtained by $\mathrm{CHNS} / \mathrm{O}$ elemental analyzer. The formula for estimating recovery percentage is given in the equation;

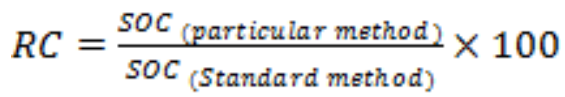

The correction factor is a compensation for the incomplete oxidation and is the inverse of recovery. It is calculated as $100 / \mathrm{RC}(\%)$.

All results were expressed on an oven-dry basis. All analyzes were done in triplicate. Data were submitted to regression correlation and Principle component analysis using Origin Pro 8.1 (2018) software.

\section{Results and Discussion}

The amount of organic $\mathrm{C}$ obtained showed differences among the studied methods (Table 1) and, as expected, were highly correlated with each other, which is in agreement with the results of previous workers (Miyazawa et al., 2000; Jankauskas et al., 2006; Pereira et al., 2006).

The mean value of SOC obtained in this study by elemental analysis, the reference method ranged from 5.71 to $98.55 \mathrm{~g} \mathrm{~kg}^{-1}$ with a mean value of $20.12 \mathrm{~g} \mathrm{~kg}^{-1}$. This analytical method has been widely used, all over the world since at the utilized combustion temperature (generally above $900^{\circ} \mathrm{C}$ ) the whole sample is entirely oxidized allowing for measurement of both organic and inorganic carbon. Of all methods, the highest values of SOC were obtained by gravimetric analysis (LOI) (Table 1) regardless of the soil type. The mass loss resulting from the volatilization of hygroscopic and structural water along with the mass of organic compounds lost in the form has $\mathrm{CO}_{2}$, has accounted for the over estimation of the organic component of the samples (Yeomans and Bremner, 1991).

In general, the methods based on wet digestion tended to underestimate the SOC level, as compared with the reference method, while the gravimetric method overestimated it, which was also observed by Sato et al., (2014). According to Walkley and Black (1934) only between 60 and $86 \%$ of the SOC is oxidized by the WB method and an average correction factor of 1.32 was applied to obtain the actual values of SOC. However, in this study a recovery of $51.03 \%$ SOC was achieved, resulting in a correction factor of 1.95 which might be due to variation in clay content, mineralogy, aggregation and the quality of the soil organic matter (Table 2).

The modified WB method based on wet oxidation, with external heating, resulted in a higher recovery $(66.76 \%)$ than WB method. The problem of incomplete digestion of the organic matter in the WB procedure was partially solved by supplying external heat during sample digestion in the modified WB protocol. Higher values of SOC by modified WB method were reported by Sato et al., (2014).

The $\mathrm{C}$ levels obtained by Heanes method was higher than the ones obtained by WB, 
modified WB and photometric methods.
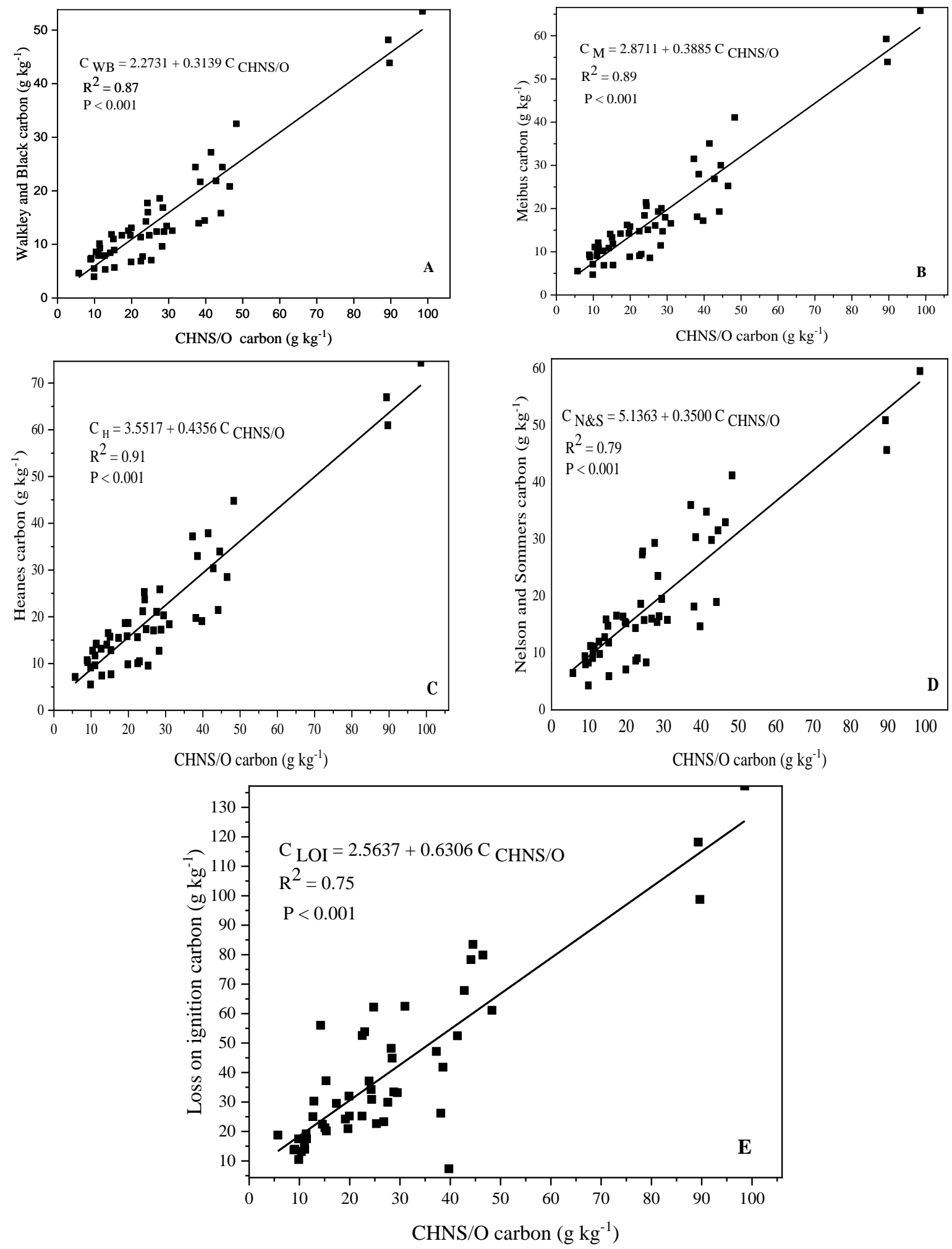

Fig.1 Regression between the carbon content of soils obtained by the reference method (CHNS/O elemental analysis) and by the comparative method A. Walkley and Black B.

Meibus C. Heanes D. Nelson and Sommers E. Loss on ignition 
Table.1 Carbon values obtained by the different methods of soil organic carbon analysis

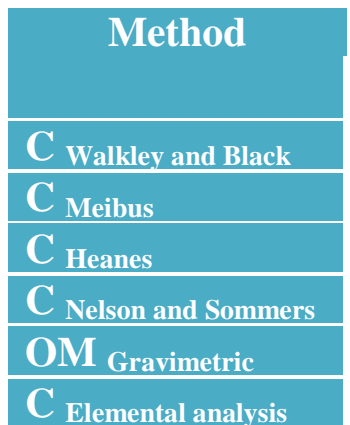

\begin{tabular}{|c|c|c|c|c|c|}
\hline Minimum & Maximum & Mean & $\begin{array}{c}\text { Standard } \\
\text { Deviation }\end{array}$ & $\begin{array}{c}\text { RC } \\
(\%)\end{array}$ & $\begin{array}{c}\text { CF } \\
(\%)\end{array}$ \\
\hline 3.96 & 53.49 & 14.77 & 10.61 & 51.03 & 1.95 \\
\hline 4.71 & 65.80 & 18.34 & 13.12 & 66.76 & 1.49 \\
\hline 5.51 & 74.35 & 20.90 & 14.72 & 74.94 & 1.33 \\
\hline 4.30 & 59.55 & 19.08 & 12.24 & 70.88 & 1.41 \\
\hline 7.31 & 137.23 & 27.84 & 27.84 & 110.13 & 0.90 \\
\hline 5.71 & 98.55 & 20.12 & 20.12 & - & - \\
\hline
\end{tabular}

Table.2 Relationship between methods of determining soil organic carbon

\begin{tabular}{|c|c|c|c|c|}
\hline \multirow{2}{*}{ Method } & \multicolumn{3}{|c|}{ Parameters of the linear regression } \\
\hline X & $\mathbf{Y}$ & $\mathbf{a}$ & $\mathbf{b}$ & $\mathbf{R}^{\mathbf{2}}$ \\
\hline \multirow{2}{*}{ CHNS/O } & WB & 2.2731 & 0.3139 & 0.87 \\
\cline { 2 - 5 } & Meibus & 2.8711 & 0.3885 & 0.89 \\
\hline & Heanes & 3.5517 & 0.4356 & 0.91 \\
\hline & Nelson \& Sommers & 5.1363 & 0.3500 & 0.79 \\
\hline
\end{tabular}

Table.3 Correlation coefficient of different soil organic carbon estimation methods

\begin{tabular}{|l|c|c|c|c|c|c|}
\hline & WB & Meibus & Heanes & N \& S & LOI & CHNS/O \\
\hline WB & 1 & & & & & \\
\hline Meibus & $0.99 * *$ & 1 & & & & \\
\hline Heanes & $0.99 * *$ & $0.99 * *$ & 1 & & & \\
\hline N \& S & $0.97 * *$ & $0.96 * *$ & $0.97 * *$ & 1 & & \\
\hline LOI & $0.82 * *$ & $0.82 * *$ & $0.82 * *$ & $0.79 * *$ & 1 & 1 \\
\hline CHNS/O & $0.94 * *$ & $0.94 * *$ & $0.93 * *$ & $0.89 * *$ & $0.87 * *$ & 1 \\
\hline
\end{tabular}

This confirms the efficiency of external heating during the digestion process, which maintains the temperature constantly during the whole oxidation process. On an average, the $\mathrm{C}$ determination by the Heanes method was $24 \%$ and Nelson and Sommers method was $15 \%$ higher than that observed by WB method. The higher recovery of the Heanes method as compared with the Walkley and Black obtained in the case of Tamil Nadu soils might be attributed to the type of organic carbon in the soils, where much is stabilized in inert form as charcoal and protected in soil micro aggregates. However, wet oxidation methods utilize toxic compounds, such as $\mathrm{Cr}^{3+}$ that are potentially hazardous for human beings and generate toxic waste that needs safe disposal (Cohen et al., 1993).

The results of Heanes method were the closet $\left(\mathrm{R}^{2}=0.91\right)$ to the results of the elemental analysis (Figure 1), justified by the external heating under digestion tube (Chatterjee et al., 2009; Conyers et al., 2011) that potentialized 
the oxidation process. The higher coefficient of regression between the two methods demonstrated that the Heanes method is reasonably effective in the recuperation of total SOC in relation to the reference method.

The photometric method (Nelson and Sommers, 1996) showed similar efficiency to Heanes method and can therefore be a viable alternative in routine laboratories, since it offers greater convenience in procedure and reproducibility, while reducing the use of toxic reagents. Furthermore, the photometric method showed positive correlation with the reference CHNS/O method $\left(\mathrm{R}^{2}=0.79\right)$. Combination of wet oxidation methods with photometric determination (Conyers et al., 2011), permitting a simpler way of determining soil organic carbon instead of titration.

The method that had lowest coefficient of linear regression with the reference method was the gravimetric method. The low $\left(\mathrm{R}^{2}=\right.$ 0.75 ) can be attributed to the large variation in mass loss. In soils the mineral fraction is greater than the organic one and part of the mineral components are hygroscopic or contain structural water. It is, therefore, likely that these soil components lose water at high temperatures (Yeomans and Bremner, 1991).

The correlation coefficient between the different soil organic carbon determinations methods are detailed in table 3. Highly significant $(0.93 * *)$ relationship was observed between CHNS/O and Heanes photometric determination methods. Walkley and Black method has lowest relationship $\left(0.82^{* *}\right)$ with loss on ignition method among all the methods.

Wider variation in the soil organic carbon by different methods was observed. The carbon content determined by the Heanes method produced the closet values to the reference method (CHNS/O elemental analysis), demonstrating greater recuperation of carbon than the other methods based on the wet oxidation. All the dichromate wet oxidation methods and loss on ignition methods was closely correlated with $\mathrm{CHNS} / \mathrm{O}$ elemental analyzer method. The photometric methods, that generate smaller volume of toxic waste, can be a potential method to substitute the Walkley and Black method, which in India is still widely used in routine soil analysis.

\section{References}

Bhattacharyya, T., P. Chandran, S. Ray, C. Mandal, P. Tiwary, D. Pal and S. Sheikh. 2015. Walkley-Black recovery factor to reassess soil organic matter: Indo-Gangetic plains and black soil region of India case studies. Communications in Soil Science and Plant Analysis, 46(20): 2628-2648.

Bhattacharyya, T., S. Ray, U. Mauryaa, P. Chandran, D. Pal, S. Durge and B. Telpande. 2015. Carbon and nitrogen estimation in soils: Standardizing methods and internal standards for $\mathrm{C} / \mathrm{N}$ analyzer. Journal of Inidan Chemical Society, 92: 263-269.

Chatterjee, A., R. Lal, L. Wielopolski, M.Z. Martin and M. Ebinger. 2009. Evaluation of different soil carbon determination methods. Critical Reviews in Plant Science, 28(3): 164178.

Cohen, M.D., B. Kargacin, C.B. Klein and M. Costa. 1993. Mechanisms of chromium carcinogenicity and toxicity. Critical Reviews in Toxicology, 23(3): 255-281.

Conyers, M., G. Poile, A. Oates, D. Waters and K. Chan. 2011. Comparison of three carbon determination methods on naturally occurring substrates and the implication for the quantification of soil carbon. Soil Research, 49(1): 27-33. 
De Vos, B., S. Lettens, B. Muys and J.A. Deckers. 2007. Walkley-Black analysis of forest soil organic carbon: recovery, limitations and uncertainty. Soil Use and Management, 23(3): 221-229.

Gelman, F., R. Binstock and L. Halicz. 2012. Application of the Walkley-Black titration for the organic carbon quantification in organic rich sedimentary rocks. Fuel, 96: 608-610.

Hesse, P.R. and P. Hesse. 1971. A textbook of soil chemical analysis. Chemical Publishing Company. London.

Jankauskas, B., A. Slepetiene, G. Jankauskiene, M.A. Fullen and C.A.A. Booth. 2006. A comparative study of analytical methodologies to determine the soil organic matter content of Lithuanian Eutric Albeluvisols. Geoderma, 136: 763-773.

Kamara, A., E.R. Rhoades and P.A. Sawyer. 2007. Dry combustion carbon, WalkleyBlack carbon and loss on ignition for aggregate size fractions on toposequence. Communications in Soil Science and Plant Analysis, 38: 20052012.

Lettens, S., B. De Vos, P. Quataert, B. Van Wesemael, B. Muys and J. Van Orshoven. 2007. Variable carbon recovery of Walkley- Black analysis and implications for national soil organic carbon accounting. European Journal of Soil Science, 58(6): 12441253.

Metson, A., L. Blakemore and D. Rhoades. 1979. Methods for the determination of soil organic carbon: a review, and application to New Zealand soils. New Zealand Journal of Science.

Mikhailova, E.A., R.R.P. Noble and C.J. Post. 2003. Comparison of soil organic carbon recovery by Walkley-Black and dry combustion methods in the Russian Chernozem. Commun. Soil Science and Plant Nutrition, 34: 1853-1860.
Nelson, D. and L. Sommers. 1982. Total carbon, organic carbon, and organic matter. In: A.L. Page et al.,(ed.) Methods of Soil Analysis. Part 2. Agronomy Monograph. 9. ASA and SSSA, Madison, WI. 539-579.

Nelson, D.W. and L.E. Sommers. 1996. Total carbon, organic carbon, and organic matter. In: C.A. Black (ed.) Methods of Soil Analysis. Part 3 - Chemical Methods. ASA and SSSA, Madison, WI. 961-1010.

Pereira, M.G., G.S. Valladares, L.H.C. Anjos, V.M. Benites, J.R.A. Espíndula and A.G. Ebeling. 2006. Organic carbon determination in histosols and soil horizons with high organic matter content from Brazil. Scientia Agricola, 63: 187-193

Sato, J. H., C.C.D. Figueiredo, R.L. Marchao, B.E. Madari, L.E.C. Benedito, J.G. Busato and D.M.D. Souza. 2014. Methods of soil organic carbon determination in Brazilian savannah soils. Scientia Agricola, 71(4): 302-308.

Schollenberger, C. 1927. A rapid approximate method for determining soil organic matter. Soil Science, 24(1): 65-68.

Tabatabai, M. and J. Bremner. 1970. Use of the Leco Automatic 70-Second Carbon Analyzer for Total Carbon Analysis of Soils 1. Soil Science Society of America Journal, 34(4): 608-610.

Tinsley, J. 1950. The determination of organic carbon in soils by dichromate mixtures. Transactions $4^{\text {th }}$ International Congress on Soil Science, (1): 161-164.

Walinga, I., M. Kithome, I. Novozamsky, V. Houba and J. Van der Lee. 1992. Spectrophotometric determination of organic carbon in soil. Communications in Soil Science and Plant Analysis, 23(15-16): 1935-1944.

Wang, X., J. Wang and J. Zhang. 2012. Comparisons of three methods for organic and inorganic carbon in 
calcareous soils of northwestern China. PLOS One, 7(8): e44334.

Walkley, A. 1947. A critical examination of a rapid method for determining organic carbon in soils-effect of variations in digestion conditions and of inorganic soil constituents. Soil Science, 63(4): 251-264.

Walkley, A. and I.A. Black. 1934. An examination of the Degtjareff method for determining soil organic matter, and a proposed modification of the chromic acid titration method. Soil Science, 37(1): 29-38.

Wright, A.L., Y. Wang and K. Reddy. 2008. Loss on ignition method to assess soil organic carbon in calcareous Everglades Wetlands. Communications in Soil Science and Plant Analysis, 39(19-20): 3074-3083.

Yeomans, J. and J. Bremner. 1991. Carbon and nitrogen analysis of soils by automated combustion techniques. Communications in Soil Science and Plant Analysis, 22(9-10): 843-850.

\section{How to cite this article:}

Ramamoorthi, V. and Meena, S. 2018. Quantification of Soil Organic Carbon - Comparison of Wet Oxidation and Dry Combustion Methods. Int.J.Curr.Microbiol.App.Sci. 7(10): 146-154. doi: https://doi.org/10.20546/ijcmas.2018.710.016 